Gut, 1986, 27, 728-733

Case report

\title{
Mesenteric lymph node cavitation in coeliac disease
}

\author{
G K T HOLMES
}

From the Department of Gastroenterology, Derbyshire Royal Infirmary, Derby

SUMmARY A patient with coeliac disease and mesenteric lymph node cavitation is reported. This is a rare occurrence and has received very little attention in the English literature.

Patients with jejunal biopsy appearances characteristic of coeliac disease may not respond to a gluten free diet because of underlying lymphoma or other malignant tumours. ${ }^{12}$ The patient reported in this paper, initially unresponsive to a gluten free diet, was thought to have developed malignancy but at laparotomy multiple, large cavitating lymph nodes were found in the small intestinal mesentery. Postoperatively, after a short period of parenteral nutrition and steroids he responded to a gluten free diet. It appears that only two similar patients, both from centres in France, have previously been reported, making this a rare occurrence in coeliac disease $^{3+}$ (same case) $^{5}$ (case 2$)$. Two other patients with mesenteric lymph node cavitation and a flat jejunal biopsy, but in addition with small intestinal ulceration, also responded to gluten withdrawal and therefore, have coeliac disease. ${ }^{56}$ All other cases with or without ulceration, treated or untreated with a gluten free diet have died. The present patient is reported to draw attention to these lymph node abnormalities which have received little attention in the English literature.

\section{Case report}

A white man, date of birth 31 May 1944, began to experience offensive diarrhoea and abdominal distension from the age of 2 years. He was not investigated until 1953, however, when a small intestinal radiograph showed flocculation of the barium. A flat glucose tolerance curve and malabsorption of fat were also found. A diagnosis of

\footnotetext{
Address for correspondence: Dr (; K T Holmes. Department of (iastroenterology. Derbyshire Royal Infirmary. Derhy DI:I 20Y.
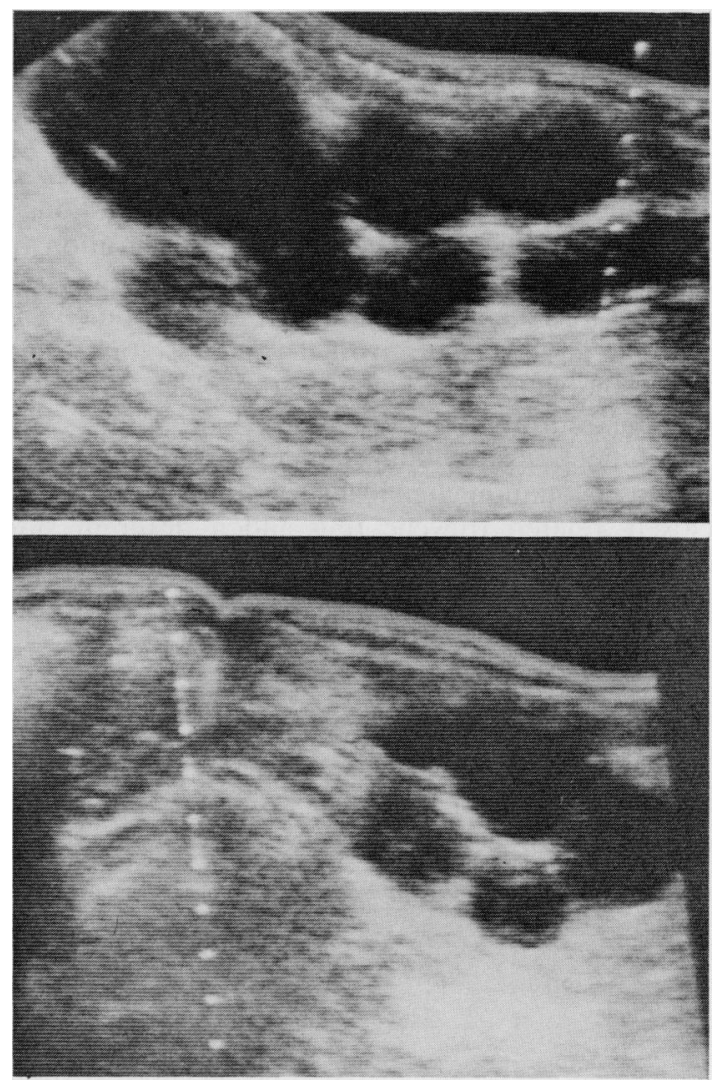

Fig. 1(a) Longitudinal ultrasound B scan of upper abdomen $5 \mathrm{~cm}$ to left of midline. Line at level of umbilicus. Interval between dots represents $1 \mathrm{~cm}$.

(b) Transverse ultrasound B scan upper abdomen left side $12 \mathrm{~cm}$ below xiphisternum. Line through midline of body. Interval between dots represents $1 \mathrm{~cm}$. 
coeliac disease was made and a low fat diet instituted, but he did not attend the outpatient department for further assessment.

At the age of 14 years there was concern about his small stature (height $141 \mathrm{~cm}$; weight $33.5 \mathrm{~kg}$ ) and he was referred to the Derbyshire Royal Infirmary. He denied any bowel symptoms but was severely anaemic with a haemoglobin of $6.5 \mathrm{~g} / \mathrm{dl}$. A glucose tolerance curve was again flat. A jejunal biopsy was not obtained but within one year of starting a gluten free diet his weight had risen to $41.3 \mathrm{~kg}$ and height to $152.5 \mathrm{~cm}$. At this time he was introducing more and more gluten into the diet without apparent ill effect and defaulted from the outpatient clinic at the end of 1961.

He remained well for the next 20 years and was employed as a bricklayer. In late 1982, however, he was referred with a four month history of pains in the legs, anorexia, diarrhoea, abdominal distension and weight loss of $6.5 \mathrm{~kg}$. On examination he was an ill-looking, emaciated man weighing $51 \cdot 6 \mathrm{~kg}$. Finger clubbing and ankle oedema were present. The abdomen was distended and a firm, fixed mass was felt in the left side. A provisional diagnosis of coeliac disease complicated by lymphoma was made. The haemoglobin was $12.5 \mathrm{~g} / \mathrm{dl}$ with target cells and Howell Jolly bodies present in the blood. Serum and red cell folate levels were very low. An abdominal ultrasound revealed a large collection of echo free areas in the left side of the abdomen indicative of cysts (Fig. 1). A barium follow through examination showed marked dilatation of the small bowel and a jejunal biopsy carried out in January 1983 was characteristic of untreated coeliac disease with total villous atrophy (Fig. 2). A gluten free diet and steroids were started but there was no clinical improvement, rather a deterioration, and a laparotomy was undertaken two weeks later to clarify the diagnosis.

The small intestinal mesentery was found to contain a large number of tense cysts of varying size containing clear or slightly blood stained fluid (Fig. $3)$. The largest was about $8 \mathrm{~cm}$ in diameter. Normal lymph nodes were also identified and a whole spectrum of abnormality from hypertrophied nodes containing a whitish liquifying material in their centres, through to large thin walled cysts holding clear or slightly turbid material. Some lacteals in the affected mesentery and over the upper small bowel were slightly dilated. The spleen was small, being only $5 \mathrm{~cm}$ in the long axis, but the other intraabdominal organs were normal. A small intestinal biopsy was taken just beyond the duodenojejunal flexure and a second was obtained below the level of the cysts in the distal jejunum. Several biopsies were taken of lymph nodes and cysts. Resection of the affected mesentery was not undertaken as this would have involved removal of approximately $120 \mathrm{~cm}$ of jejunum. Instead the cysts were decompressed by aspiration and the abdomen closed. The cyst fluid was sent for microscopy and culture.

Histological examination of the jejunal biopsy

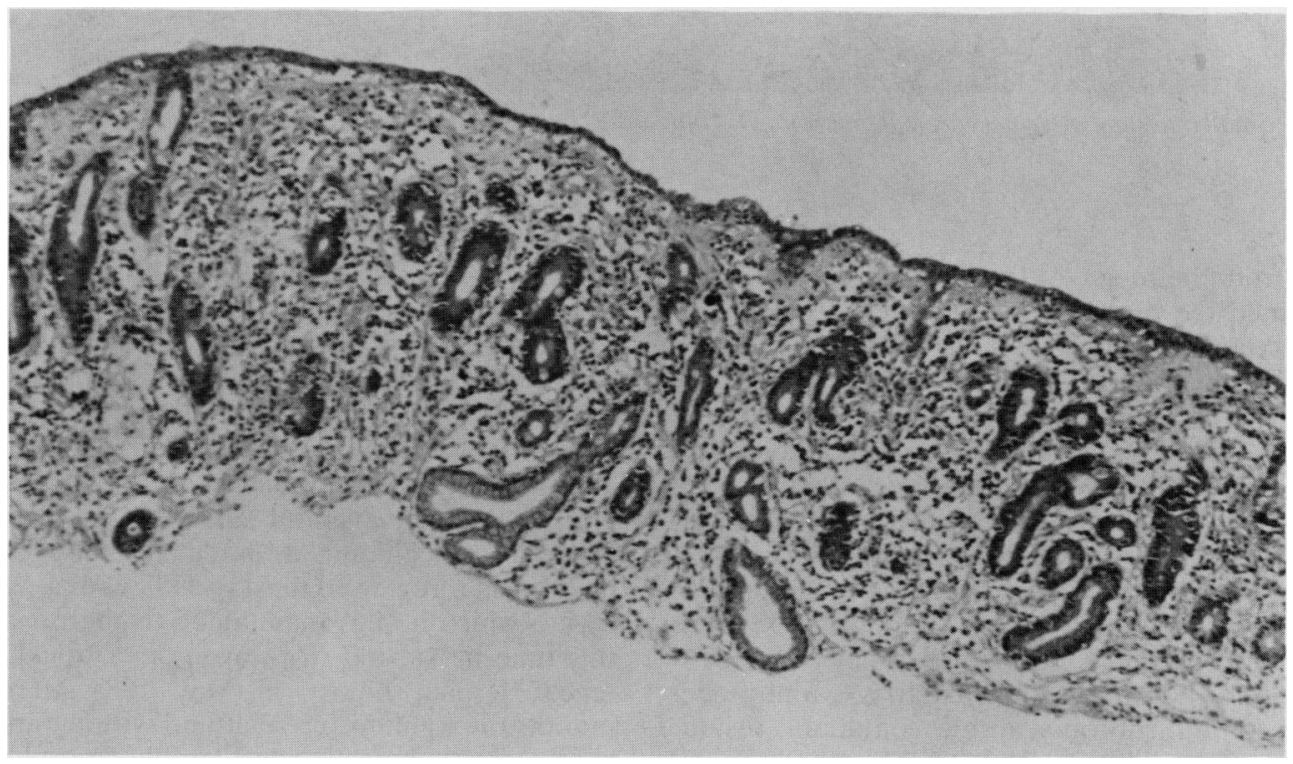

Fig. 2 Flat jejunal biopsy of untreated coeliac disease. 


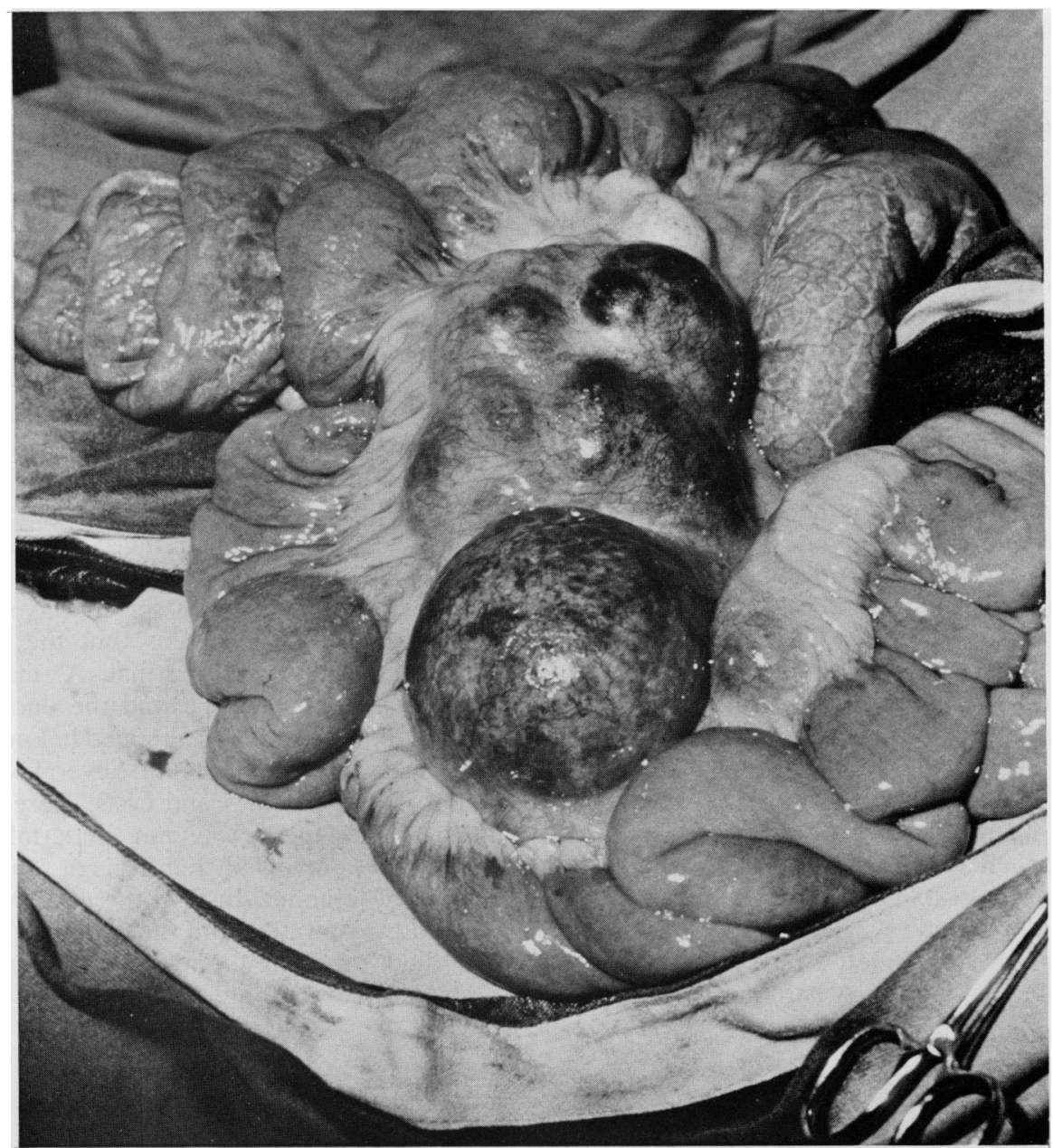

Fig. 3 Small intestinal mesentery seen at laparotomy containing large cavitating lymph nodes.

taken from the region of the duodenojejunal flexure confirmed the presence of total villous atrophy. A few atypical histiocytes or reticulum cells were found in the lamina propria, but lysozyme and alpha-1-antitrypsin markers were negative. Whether these morphological changes represent a prelymphomatous condition cannot be excluded. No similar cells were discovered in the other intestinal biopsies or the lymph node structures. In the more distal jejunal mucosa short, broad villi were present. There was no evidence of Whipple's disease or congenital lymphangiectasia. Histology of the cystic lesions showed these to be cavitating lymph nodes. A surrounding fibrous capsule containing residual foci of lymphoid tissue was easily identified (Fig. 4). Microscopy of the cyst fluid revealed only a few red blood cells and debris. There was no growth on culture and no evidence of tuberculosis.

Postoperatively, because of the patient's weakened condition, parenteral nutrition was administered for two weeks with obvious benefit. By the end of this period he was well established on a gluten free diet and the steroids were stopped. His subsequent progress was uneventful and he was discharged home at the beginning of March. He was in excellent health when reviewed in May 1983 with a weight of $60 \mathrm{~kg}$, which he has maintained to the present. At this time he started work again as a bricklayer. A repeat jejunal biopsy in May 1983 after three months on a gluten free diet and without any other medication, showed considerable morphological improvement with the return of villi (Fig. 5). At 


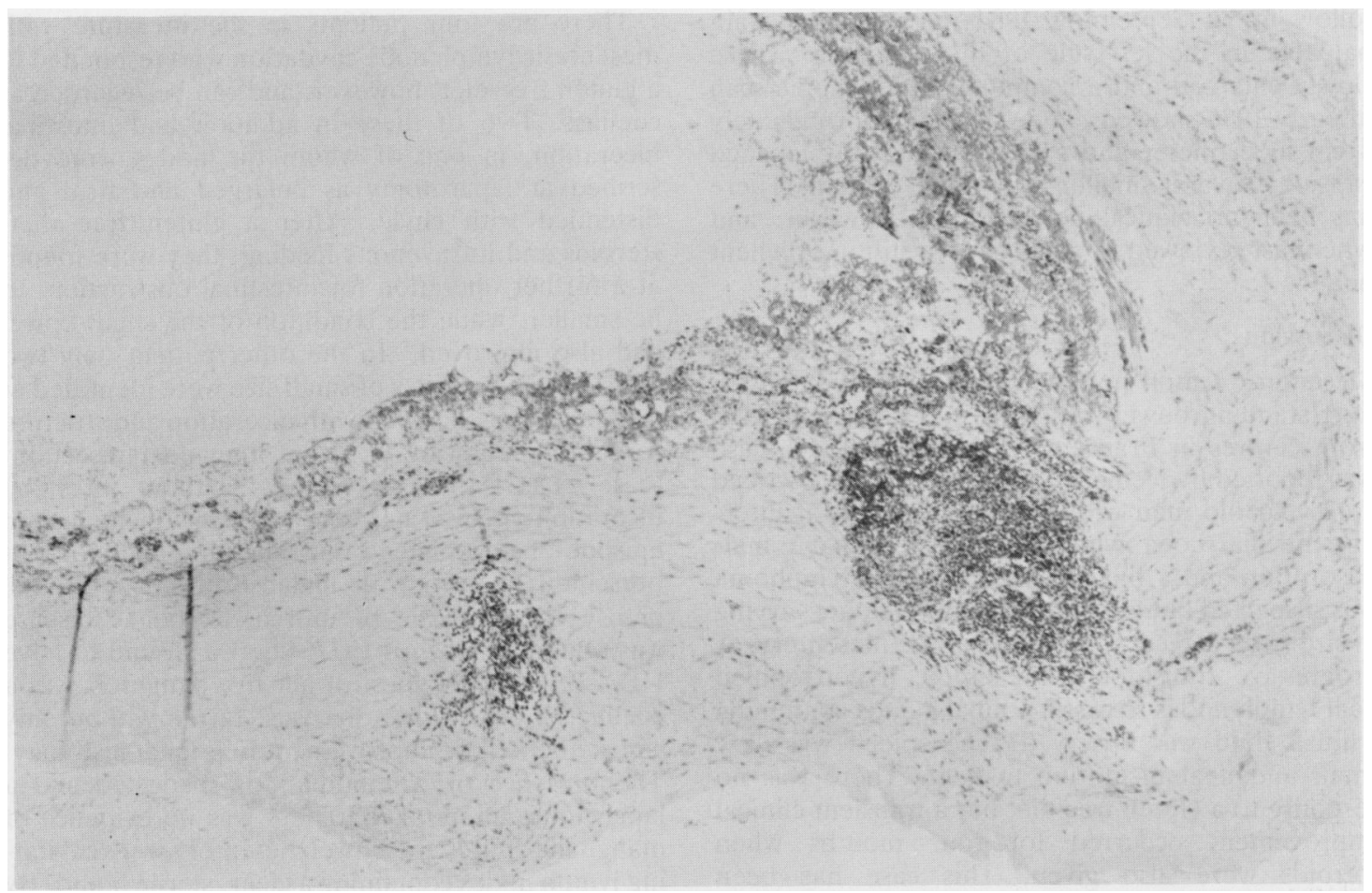

Fig. 4 Cyst wall showing the fibrous capsule and lymphoid foci.

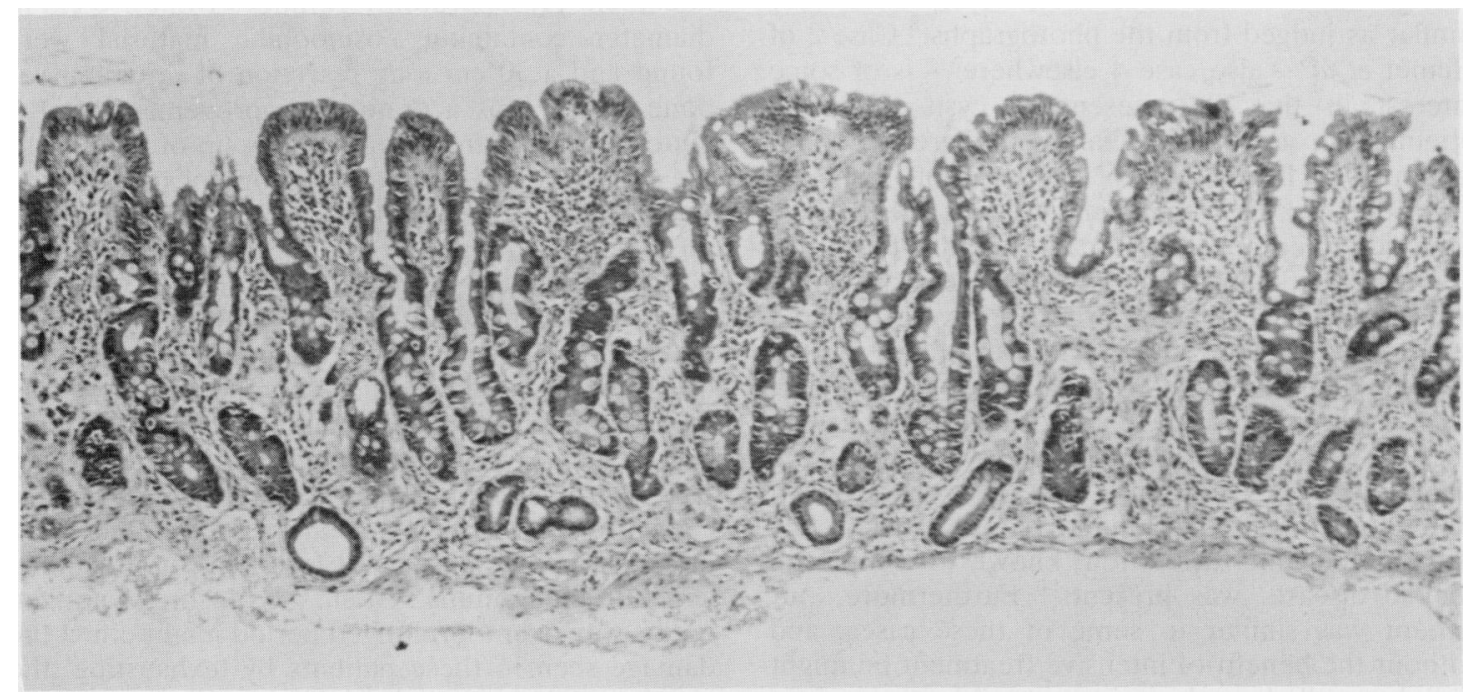

Fig. 5 Jejunal biopsy after three months of a gluten free diet showing considerable morphological improvement. 
follow up in September 1984 masses were again palpable in the left side of the abdomen. These slowly enlarged and a computed tomographic scan in early 1986 showed two cysts each approximately $4 \mathrm{~cm}$ in diameter and surrounded by a thickened capsule. Several smaller cysts were evident. There has been no clinical deterioration, however, and when last reviewed in April he was still in excellent health.

\section{Discussion}

Mesenteric lymph node cavitation in patients with long standing bowel symptoms has been described from centres in France. ${ }^{3-5}$ 7-10 The first such case was reported by Hemet et al in $1969 .^{7}$ They described a 42 year old man with a 20 year history of intermittent diarrhoea who was found to have malabsorption and a flat jejunal biopsy. A lymphoma was suspected but at laparotomy 20 tumours varying in size from 2-8 cm were found in the mesentery. A progressive transition from simple hypertrophied ileal lymph nodes to cystic jejunal glands containing whitish fluid was observed. The spleen was very small and ileal ulceration evident. There was no response to a gluten free diet but a transient clinical improvement occurred for four months when steroids were also given. This case has been enlarged on ${ }^{8}$ and is case 5 in a further publication. ${ }^{5}$ The patient died from cachexia in July 1967, four months after laparotomy and the findings were confirmed at necropsy. Extra abdominal nodes were all normal. This patient resembles our case in a number of aspects, particularly with regard to the long history and the progressive transition of change seen in the nodes. The cysts were very similar as judged from the photographs. ${ }^{8}$ Case 2 of Hemet et $a l^{8}-$ also case 4 elsewhere ${ }^{5}$ is of some interest in that the mesenteric cysts, although originally up to $7 \mathrm{~cm}$ in diameter, regressed spontaneously. There was no evidence of intestinal ulceration in this woman and other patients have been described both with ${ }^{5}$ (case 3 ) and without this finding ${ }^{5}$ (case 1). ${ }^{9}$ In none of these cases was there a sustained clinical response or an improvement in the jejunal mucosa after gluten withdrawal and all died of cachexia or infection. While a diagnosis of coeliac disease was not proven in any of this group, it was possibly the underlying diagnosis. All had long standing bowel symptoms, sometimes dating from childhood, and a flat jejunal biopsy, and in two patients intestinal ulceration, known to complicate coeliac disease, was present. ${ }^{11}$ Furthermore, our patient was similar to some of these cases, and without the benefit of intensive treatment he might well have died, making it impossible to confirm coeliac disease as the diagnosis.
There are four patients in the literature with mesenteric lymph node cavitation who responded to a gluten free diet, however, and can be regarded as coeliacs. Two of these in addition had intestinal ulceration, in one of whom the nodes were described at laparotomy as enlarged and firm and distended with chyle. After a gluten free diet, steroids and intravenous feeding, they were found, at a further operation for intestinal obstruction, to be smaller, while the condition of the small bowel had also improved. ${ }^{6}$ In the other patient only two affected lymph nodes of small size were identified at ileal level in association with ulceration and stricture formation requiring a $35 \mathrm{~cm}$ long ileal resection ${ }^{5}$ (case 6). Of the two patients without intestinal ulceration one was a 41 year old woman who had an episode of unexplained diarrhoea in childhood but presented in 1976 with malabsorption. A jejunal biopsy characteristic of untreated coeliac disease was obtained in April 1977. She was found to have HLA-B8 and the eldest of her five daughters was a coeliac. A gluten free diet was started without any clinical benefit or improvement in jejunal histology. The presence of lymphoma was suspected and a laparotomy undertaken. There was no evidence of malignancy but in the bowel mesentery were cavitating lymph nodes containing a clear, sterile liquid. By September 1979, after 26 months of a gluten free diet and 15 months of steroid therapy, the patient was well with a normal jejunal mucosa. This was still the position 14 months after stopping the prednisolone $^{34}$ (case 1). The second patient ${ }^{5}$ (case 2), a 63 year old woman with chronic diarrhoea presented with a mass in the left side of the abdomen. At laparotomy 12 nodes from $2-6 \mathrm{~cm}$ in diameter containing eosinophilic material were found and a $30 \mathrm{~cm}$ long resection of jejunum was done. There was a dramatic improvement after a gluten free diet and after a follow up of 18 months the cysts have not returned. Photographs of the cysts show them to be identical to those seen in the present case, but unlike the present case they have not recurred.

It is not clear why these cysts form. Infection is unlikely and there is no evidence that malignant histiocytosis is responsible. Bombardment of the mesenteric lymph nodes by antigenic material crossing a damaged intestinal mucosa is a possibility particularly as immunological disturbances occur in coeliac disease which appear to reflect increased intestinal permeability with foreign protein gaining access to the immune system. ${ }^{12}$ Exposure to antigen in this way over a prolonged period might effect the damage seen in these patients by 'exhausting' the glands and destroying their cellular elements. It is of interest in this regard that the nodes most affected 
are found in the jejunal mesentery serving that part of the small intestinal mucosa which is damaged in untreated coeliac disease. Although gluten might play a part in the pathogenesis it cannot be the whole explanation for in our patient cystic change has continued while he was taking a strict gluten free diet.

At operation the cysts may be decompressed by aspiration as in our case or the affected mesentery resected. In the patient where resection was carried out, the cysts have not recurred after a follow up of 18 months, but we found it difficult to justify an extensive removal of bowel for a benign condition. Although in our patient the cysts have returned he remains in excellent health. Only time will tell what the future holds and resection is still an option.

The presence of mesenteric lymph node cavitation in coeliac disease is rare and can be added to the list of conditions complicating this disorder which may prevent response to a gluten free diet either transiently as in this case, or permanently, leading to death. With the use of ultrasound machines and computed tomography scanners, cysts will be easy to visualise and should be sought in any patient with a flat jejunal biopsy who does not show the expected response to a gluten free diet. Laparotomy is likely to be required to clarify the diagnosis.

I am grateful to Dr I Hopper and Dr H Thompson for reviewing the histology.

\section{References}

1 Holmes GKT, Stokes PL, Sorahan TM, Prior P, . Waterhouse JAH, Cooke WT. Coeliac disease, gluten free diet and malignancy. Gut 1976; 17: 612-9.

2 Cooper BT, Holmes GKT, Cooke WT. Lymphoma risk in coeliac disease of later life. Digestion 1982; 23: 89-92.
3 Hoang C, Galian A, Maitre F, Degois T, Celerier M, Modigliani R. Atrophie villositaire totale, cavitation ganglionnaire mésentérique, atrophie splénique. Forme particulière de la maladie coeliaque de l'adulte, à propos d'un nouveau cas. Ann Pathol 1983; 3: 251-6.

4 Salmeron M, Modigliani R, Galian A et al. La laparotomie exploratrice est-elle indiquée dans les atrophies villositaires totales de l'intestin grêle, résistantes cliniquement et histologiquement au régime sans gluten et a la nutrition parentérale exclusive? Gastroenterol Clin Biol 1982; 6: 996-1002.

5 Matuchansky C, Colin R, Hemet J et al. Cavitation of mesenteric lymph nodes, splenic atrophy and a flat small intestinal mucosa. Report of six cases. Gastroenterology 1984; 87: 606-14.

6 Jones PE, Gleeson MH. Mucosal ulceration and mesenteric lymphadenopathy in coeliac disease. $\mathrm{Br}$ Med J 1973; 3: 212-3.

7 Hemet J, Bourquelot R, Colin R. Malabsorption et cavitation mésentérique. [Abstract]. Arch Anat Pathol 1969; 17: A115-8.

8 Colin R, Hemet J, Geffroy Y. Atrophie villositaire primitive. Cavitation ganglionnaire mésentérique. Atrophie splénique. A propos d'un cas. Arch Fr Mal App Dig 1972; 61: 451-62.

9 Marche C, Bocquet L, Mignon M, Preel JL. Syndrome de malabsorption avec cavitation ganglionnaire mésentérique et atrophie splénique. A propos d'une nouvelle observation anatomo-clinique. Sem Hop Paris 1974; 50: $879-86$.

10 Wolf JL, Lacroute JM, Baumann R, Weill-Bousson M, Weill JP. Atrophie villositaire intestinale et cavitation ganglionnaire mésentérique. Revue de la litterature et presentation d'un nouveau cas. [Abstract]. Gastroenterol Clin Biol 1980; 4: 254A.

11 Bayless TM, Kapelowitz RF, Shelley WM, Ballinger WF, Hendrix TR. Intestinal ulceration - a complication of coeliac disease. $N$ Engl J Med 1967; 276: 996-1002.

12 Cooke WT, Holmes GKT. Immunology. In: Coeliac disease. Edinburgh: Churchill-Livingstone, 1984: 247-63. 